\title{
The role of corporate foresight in exploring new markets - evidence from 3 case studies in the BOP markets
}

\author{
Jakob Højland \\ Department of Management, Aarhus University, Aarhus, Denmark \\ René Rohrbeck \\ Department of Management, Aarhus University, Aarhus, Denmark
}

\begin{abstract}
We examine to what extent successful business-development activities in uncertain environments can be classified as corporate foresight (CF) and to what extent they have been intentional and systematic. Beginning with identifying successful cases of new-business development in Bottom of the Pyramid markets, we use various data sources to reconstruct timelines and map CF activities. We selected the cases to maximise their heterogeneity in firm size, industry, nature of the product and ownership structure. Our findings suggest that the probing (experimental search) phase is particularly important in unknown and uncertain environments but that perceiving and prospecting (cognitive search) activities are necessary to find distant opportunities. In addition, we find that successful business-development activities rely on multiple iterations between perceiving, prospecting and probing. Our findings emphasize that CF should include activities that encompass both experimental and cognitive search elements.
\end{abstract}

Keywords: Corporate Foresight, Business Development, Cognitive Search, Experimental Search.

\section{Introduction}

Over the last decade, technological development such as digitalization and the Internet of Things (IoT) have created novel opportunity spaces that are now being explored by firms to develop attractive new markets. Simultaneously, these developments disrupt established industries in which emerging technologies alter the existing rules of the game and enable entirely new business models (Johnson, Christensen, and Kagermann 2008). The increased speed and complexity of today's business environment calls for novel approaches that permit the anticipation and interpretation of trends and the use of the insights gained for a competitive advantage (Tsoukas and Shepherd 2004; Coates, Durance, and Godet 2010). In the past two decades, an increasing number of companies have built corporate foresight (CF) capabilities (Daheim and Uerz 2008). During this time, CF practices have evolved from specific deployment of methods and processes to being organizationally integrated and becoming a key component of the future preparedness of organizations (Rohrbeck, Battistella, and Huizingh 2015).

CF practices have been shown to be an important predictor for superior profitability and market valuation growth (Rohrbeck, Kum, and Jissink 2017). Through systematic CF practices, firms can overcome cognitive and action-level inertia (Gavetti 2012). CF practices permit the identification of superior courses of action and foreseeing their consequences (Gavetti and Menon 2016), which can help on the strategy level as well as on the level of innovating new products, services, and business models (Rohrbeck and Gemünden 2011; Heger and Rohrbeck 2012). While CF has been shown to create value in saturated Western 
markets (Rohrbeck 2012; Rohrbeck and Schwarz 2013), there are no similar studies that replicate the finding in developing markets.

In this paper, we investigate three cases of successful market exploration in a particularly challenging segment characterized by a high number of consumers with very low spending power. Such markets have become known as the Bottom of the Pyramid (BOP) segment (Prahalad and Hart 2002).

In the following we will first discuss the literature and introduce our analytical framework. In section 3 we explain our research approach. In section 4 we first analyse our three cases using timelines and our analytical framework and then report on the cross-case analysis. In section 5 we discuss our findings and discuss future research directions.

\section{Building a framework for corporate foresight in BOP markets}

\subsection{Corporate foresight}

$\mathrm{CF}$ has been regarded as an organizational ability, set of practices and process (Slaughter 1997; Becker 2002; Rohrbeck 2010a; Hines and Bischop 2006). In this paper, we conceptualize $\mathrm{CF}$ as a set of practices that support new business exploration through identifying drivers of change (perceiving), interpreting the consequences of the drivers both individually and collectively (prospecting), and actions that permit the testing of value propositions, product/service designs and market acceptance (probing).

Perceiving often starts with the acceptance that firms need to build specialized sensors that reduce blind spots in their peripheral vision (Day and Schoemaker 2004; Winter 2004). The aim is to identify the majority, if not all, of relevant change drivers in a given market space and gain a lead-time advantage towards competitors (Rohrbeck 2010b). The outcome of the perceiving process is a list of weak and strong signals of change, trends, critical events and strategic surprises (Peter \& Jarret, 2015) rated by relevance for the firm. Often, firms will also organize them on dimensions such as the level of uncertainty, impact, maturity or domains. In that respect, we define uncertainty as the inability to anticipate the likely evolution of drivers of change in the business environment, which can be reduced to a certain extent though structured CF practices (Vecchiato \& Roveda, 2010).

Prospecting includes practices that translate signals into insights. Insights are created through interpreting the signal and the consequences for the focal firm. In new market exploration, a particular focus is on identifying systemic effects, in which multiple drivers are interdependent, mutually reinforcing and able to trigger exponential change. This phenomenon has previously been described as the S-Curve and is today also often called the tipping point. The tipping point is the moment that a product or service becomes mainstream, is publicly accepted and sees exponential growth in demand (Gladwell, 2002). Prospecting involves the usage of structured methods such as scenarios, roadmaps or systems-dynamics analysis to anticipate potential and plausible development trajectories that can inform the decision on the course of actions (Gavetti and Menon 2016). Prospecting practices allow the firm to reduce the effect of uncertainty, i.e., the lack of knowledge about the consequences of a change. Furthermore, it is the basis for reducing response uncertainty, which is the inability to identify viable responses in a given situation and understand the consequences of the choice (Vecchiato and Roveda 2010). Ultimately, the response is shaped by the bounded rationality of decision makers, as their capability to make rational decisions is limited by past experiences and current knowledge (Vecchiato 2015).

Probing practices are designed to trigger meaningful organizational responses to change. Probing is the first phase of direct action. This action can be a direct response to the insights 
generated in the perceiving and prospecting phases, or it can be part of an experimental search scheme in which firms experiment to gain insights (Gavetti and Levinthal 2000). Examples of probing are initial prototyping, R\&D projects, establishments of strategic partnerships and consumer tests with novel products. The nature of these actions differs across industries. Increasingly, firms are also using external venturing schemes to experiment outside of the firms' boundaries or through internal venturing, in which teams of the firms' own employees are supported in building a new solutions, products or businesses (Rohrbeck, Döhler, and Arnold 2009). Probing is an action-based approach that complements the practices of perceiving and prospecting.

While the phases are building on each other, they do not necessarily occur in a linear sequence; rather, they are complementary phases that can form part of an iterative mechanism that translates signals into insights and action. Firms that regularly iterate between phases will profit from powerful learning loops (Gavetti and Levinthal 2000).

\subsection{Bottom of the Pyramid}

The reduction of market protection mechanisms and the consequent openings of economies around the globe have radically transformed the way business is done today (Prahalad and Hart 2002). Firms are facing challenges in the form of increased competition and slowing growth in developed markets, which has forced businesses to be creative and look into the potential in new and less-developed markets in the global economy (Prahalad and Hart 2002). Still, few take the leap and realize the potential for the growing consumer segment of the world's more than 4 billion people living for \$2-4 a day, which is known as the BOP segment (Dansk Industri 2007).

For our analysis, we define three individual paths for developing BOP business opportunities.

Building a Market through Local Co-Creation and Deep Dialogue emphasizes that in the BOP segments, markets need to be built together with the consumers. According to Prahalad \& Hart (2002), this often includes the need to provide access to credit and increase the earning potential of the poor. Another method to increase purchasing power is to introduce pay-as-you-go business models or single-serve packages to address the buying power issue of the BOP segment (Prahalad and Hart 2002; Dansk Industri 2007). Simanis and Hart (2008) suggest a strategy called the BOP protocol, the first step of which is to open the market and overcome barriers through deep dialogue with local stakeholders to increase the firm's credibility and transparency in the new local market.

Creating a Sustainable Value and Distribution Chain emphasizes the creation of a sustainable business model and achieving scale in all parts of the value chain from production to distribution to ensure the long-term viability of the business model (Dansk Industri 2007). When scaling in all parts of the value chain, it is possible for the focal firm to drive down costs to accommodate the available funds of the BOP consumer (Dansk Industri 2007). Prahalad and Hart (2002) argue that firms need to invest and promote sustainable development beginning with the BOP segment. This builds credibility and will later have great influence on the consumers in Tier 1, i.e., the most financially affluent in society. Furthermore, it is important to improve access to the BOP, which is geographically dispersed to be sustainable in distribution networks and communication across geographical areas (Prahalad and Hart 2002). Therefore, MNCs either need to be creative and establish ties directly to the end consumer or, more likely, partner with a local champion in the BOP market to navigate through the complexity of the distribution and value chain.

Create Tailored Product Offerings Profitably emphasizes that firms should be able to adapt their product offerings to accommodate the tastes and budgets of local consumers. According to Prahalad and Hart (2002), this product adaptation to local markets and cultures should be 
driven through collaboration with local consumers. In that respect, Simanis and Hart (2008) argue that this is the time for the company to move into the enterprise 'creation mode', which is where the profitable business is created, i.e., not through simply expanding their existing offerings to new regional markets. This adaptation is also key to achieving scale in the value and distribution chain, which can be expected as a prerequisite for the firm to achieve profitability on their products.

Closing the loop on this BOP section and the main topic of CF, we argue that the level and structure of $\mathrm{CF}$ activities in firms create the foundation for the BOP business-development phase, as illustrated in our conceptual framework in Figure 1.

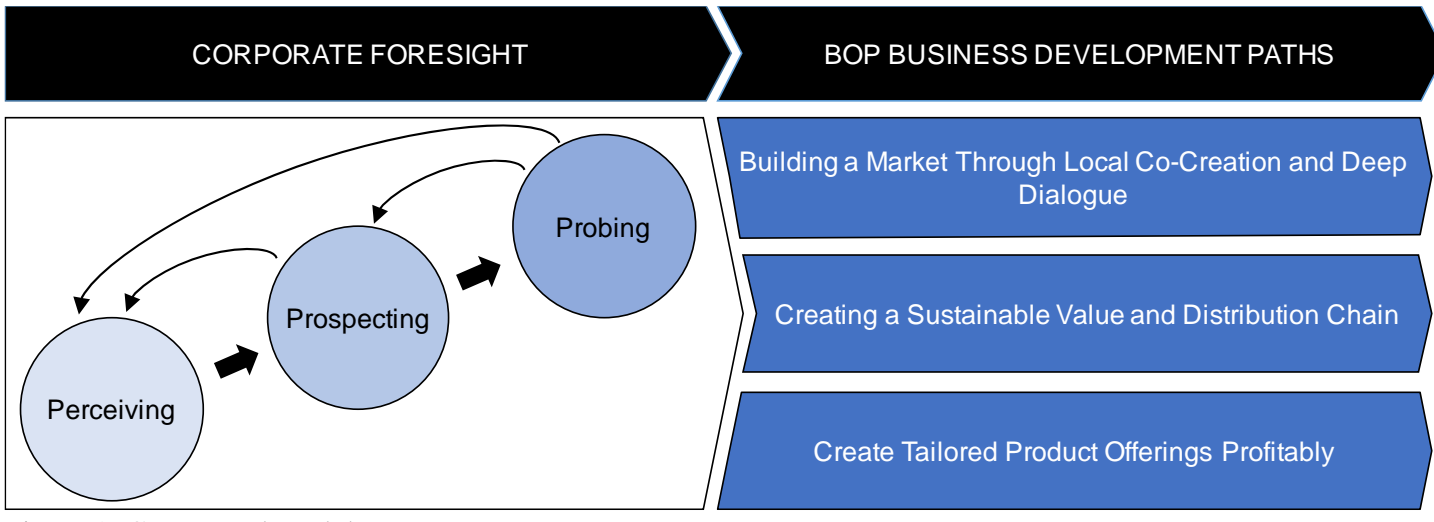

Figure 1: Conceptual model

We employ this conceptual model as a research lens through which we observe and discuss the actual business-development sequence.

\section{Research approach}

In our research, we investigate the question to which role deliberate \& structured vs. unstructured CF play in the exploration of new markets in uncertain environments. We use $\mathrm{CF}$ practices and the BOP-paths frameworks as guides for deductive reasoning but enter the field with open interview guides and openness towards uncovering alternative explanations (Saunders, Lewis, and Thornhill 2007).

\subsection{Research setting and case selection}

In our study we have applied a maximum-variation criteria to identify cases which were different on size, industry and ownership structure, see Table 1 (Eisenhardt 1989). The maximum variation also boosts the generalizability of our findings beyond the context of a single firm (Eriksson and Kovalainen 2008; Flyvbjerg 2006; Yin 2003).

Table 1: Overview cases

\begin{tabular}{rccc}
\hline & Evershelter & Kamstrup & Arla \\
\hline Industry & Aid \& relief & Engineering & Food \& beverage \\
\hline $\begin{array}{r}\text { Industry } \\
\text { characteristics }\end{array}$ & $\begin{array}{c}\text { Heavily influenced by } \\
\text { regulation }\end{array}$ & $\begin{array}{c}\text { Reliance on high-tech } \\
\text { components }\end{array}$ & $\begin{array}{c}\text { High interdependencies } \\
\text { between product and } \\
\text { production process }\end{array}$ \\
\hline $\begin{array}{r}\text { Nature of } \\
\text { product }\end{array}$ & New to the world & New to Africa & New to Africa \\
\cline { 2 - 4 } & Market pull & Technology push & Market pull \\
\cline { 2 - 4 } Size & Small for BOP market & Adapted to BOP market & Adapted to BOP market \\
\hline
\end{tabular}




\begin{tabular}{|c|c|c|c|}
\hline $\begin{array}{l}\text { Ownership } \\
\text { structure }\end{array}$ & Privately owned & $\begin{array}{c}\text { Owned by large energy } \\
\text { company }\end{array}$ & Cooperative \\
\hline
\end{tabular}

In addition, we tested that the cases meet three criteria: (a) benefitting the BOP segment, (b) operating in Africa, and (c) the accessibility of key employees involved in the process of developing the business.

\subsection{Data collection, reduction and coding}

For our data collection, we built on secondary data from reports and internal documents in addition to face-to-face and phone interviews (Rubin and Rubin 2005). For the interview, we relied on semi-structured questionnaires and the draft timelines that we had prepared on the basis of the secondary data. In total, eight interviews were conducted: two from each case company, which included always the main responsible for the business development activity and one team member. In addition, we interviewed for triangulation one international expert on the BOP segment and one Danish business-in-Africa experts.

The processing of the data followed in the first step deductive principles using the key constructs of CF and the BOP paths as a form of thematic coding (Eriksson and Kovalainen 2008). In the second round of coding, we manually reviewed all transcripts to identify additional areas of interest. This coding was driven by more openness towards new patterns and emergent findings using inductive reasoning (Eisenhardt 1989). We applied this twophase data-reduction and coding process first to the within-case level and then to our crosscase analysis.

\section{Results}

In the results section, we will first present our within-case findings for all three cases. In section 4.4 we then discuss the extent to which the practices have contributed to the success of the business-development activity. Special attention is placed on market entry and business-model adaptation. Where we conceptualize 'business model', as the architectural setup a firm uses to define a compelling value proposition and create and capture value (Johnson, Christensen, and Kagermann 2008).

\subsection{Start-up company in housing industry (EverShelter)}

Our first case, Evershelter, is a start-up that produces shelter solutions for displaced people. The firm operates in the aid-and-relief industry, serving the BOP segment by providing an alternative to other temporary housing solutions, which are primarily tents.

Figure 2 shows the sequence of the actual business-development activities. It can be seen that the early perceiving (step 1) was the result of an unsystematic activity. The initial idea was triggered by a long-term housing project for refugees for which the father of the CEO of Evershelter (JC) was responsible. JC explained that he initially became interested when he saw reports about refugees. He then realized that technology today can enable alternative solutions to tents that would be 'more robust and which could hold longer [...]'. This was particularly relevant, as refugees stayed increasingly longer in camps (at that time an average of 15 years) that were designed to be short-term shelters and not long-term housing. At that stage, JC was still acting alone and started to perform his own prospecting (step 2), beginning with technology scanning and looking on the Internet for alternatives to tents and mapping possible technical solutions. On that quest, he uncovered a potential technology provider in Denmark and moved on to investigate the market. To further explore the viability of the business opportunity, JC reviewed refugee statistics from the UN, finding that the number of people living in refugee camps was starting to grow dramatically, increasing his hope of 
doing good and simultaneously providing a viable business opportunity. For probing (step 3), JC used the opportunity that he was enrolled in a master's course on disaster relieve, in which the other participants were all 'experienced camp people, who had flown in from around the world $[\ldots]$ and I just got a lot of great feedback'.

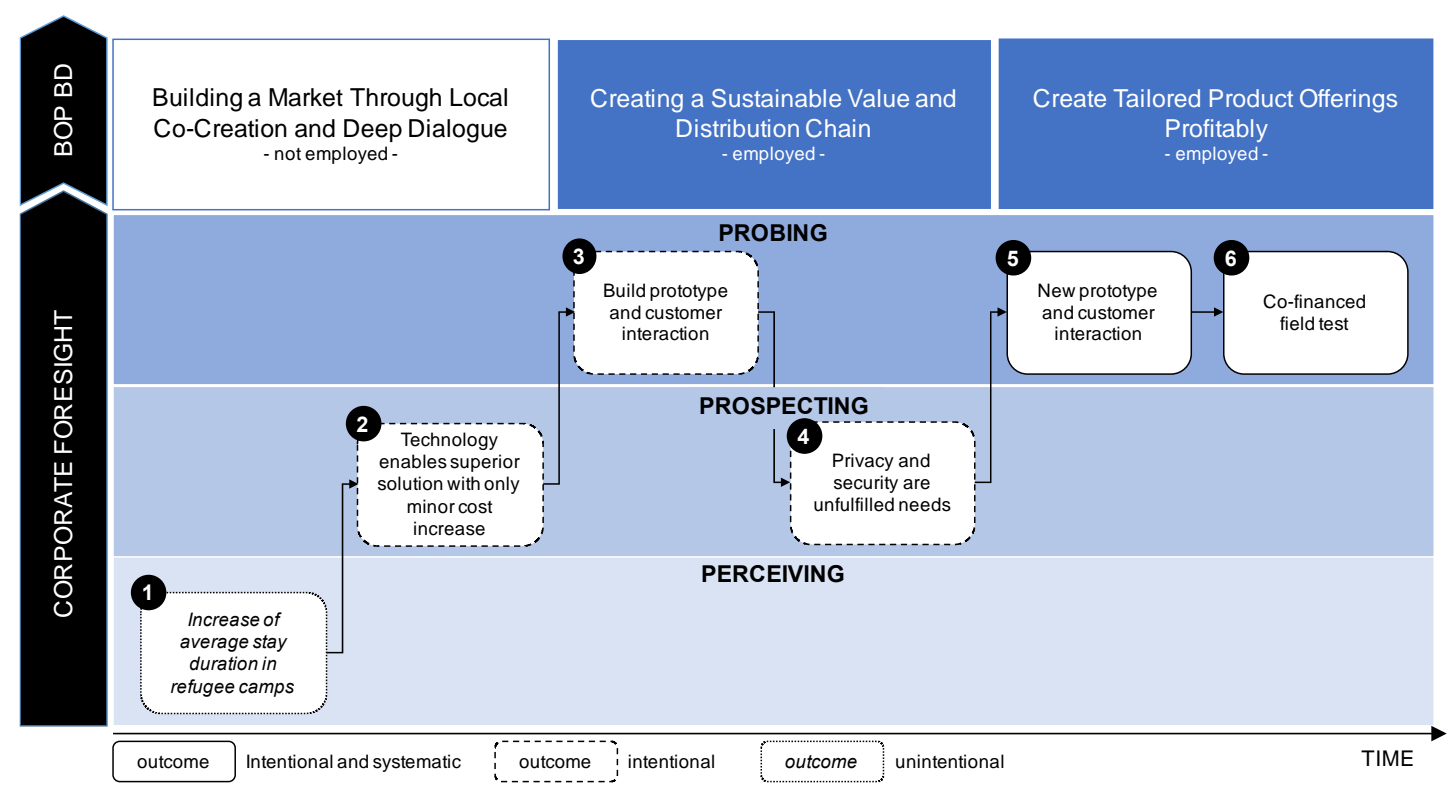

Figure 2: Business development sequence - Evershelter

With encouraging feedback on the first prototype, JC was able to find a first innovation incubator that provided $60 \%$ of the investment for building the first prototype. At the same time, he found with Real Relief a complementary business partner that was headed by a wellrespected and innovative business woman from the aid-and-relief industry, according to one of the interviewed experts on Africa. This partnership brought significantly more insight into the shelter business and consequently helped create through prospecting (step 4) a deeper understanding of the future business model and the elements that would be crucial for a solution and commercial success. Among these, it was discovered that the tents lacked privacy and security, which are particularly important for long-term residents. With this reinforced understanding, the second round of probing (step 5) was prepared with the development of a more stable prototype. With this prototype, they engaged in field tests, which included one unit in Iraq that subsequently was expanded to 33 and 14 in Uganda. This probing was made possible through the 'Dansk Flygtningehjælp'. This second probing phase also led to two major product improvements: making the doors lockable and allowing them to let more light through. Finally, in the third probing phase (step 6), further improvements were investigated, including designs to make the shelter earthquake proof. This probing was effectuated by involving the Universities of Aarhus and Copenhagen, which also allowed the limiting of costs and ensured the use of state-of-the-art technology.

With regards to the BOP business-development activities, we attest that Evershelter has mostly used two of the three paths.

- They embraced the creating a sustainable value and distribution chain through engaging in the partnership with Real Relief and with the Danske Flygtningehjælp to build a value chain reaching all the way to the end customer.

- They also worked on creating tailored product offerings profitably by starting their development with the end customer with the BOP needs (security and privacy) in mind.

When looking at how intentional and systematic the practices were, we can find a typical start-up pattern in which the initial value proposition idea is not derived from a systematic approach but from a person-specific insight that was picked up unintentionally. In the later 
stages, one could have expected that the more the company needs to rely on partnerships and external funding, the more it would need to engage in more structured prospecting activities. Here, however, the approach was still heavily instinct driven, which the head of Real Relief commented on as a potential reason for missing valuable opportunities. However, the last two phases were both intentional and systematic.

\subsection{Multinational corporation in the engineering industry (Kamstrup)}

Our second case, Kamstrup, is a world-leading company within the industry of intelligent metering solutions, operating in 24 countries worldwide as a direct supplier for energy and utility companies. Since 2009, Kamstrup has served the African market, including the BOP segment.

In the case of Kamstrup, we would expect that, as an established firm owned by an even larger mother company, it would have a more structured approach to new business development than our first start-up case. Indeed, the perceiving activities are following an intentional and systematic practice that is the business-development team drives. The practice consists of using external networks and reports from think tanks and media-monitoring data. Of the perceiving function, key elements are outsourced to external consultants and futurists.

Figure 3 gives an overview of the business-development activities. As a result of the initial perceiving activity (step 1) several mega trends were identified, one of which was the lack of access to electricity in developing countries. In many countries, this trend had already triggered meaningful governmental and NGO activities. In some parts of Africa, the share of consumers with access to electricity is as low as 30\%. Consequently, many African utility companies are actively seeking smart energy management solutions, which triggered probing activities (step 2) in Kamstrup. These probing activities consist of product adaptations to the local needs. Whereas these probing activities ensured that the solution-market fit was enhanced, it was not sufficient to enter into large-scale contracts, and the businessdevelopment activities in Africa moved back to the prospecting phase (step 3). The prospecting effort was aimed at predicting and managing the tipping point, which would pave the way for large-scale adoption of smart energy solutions.

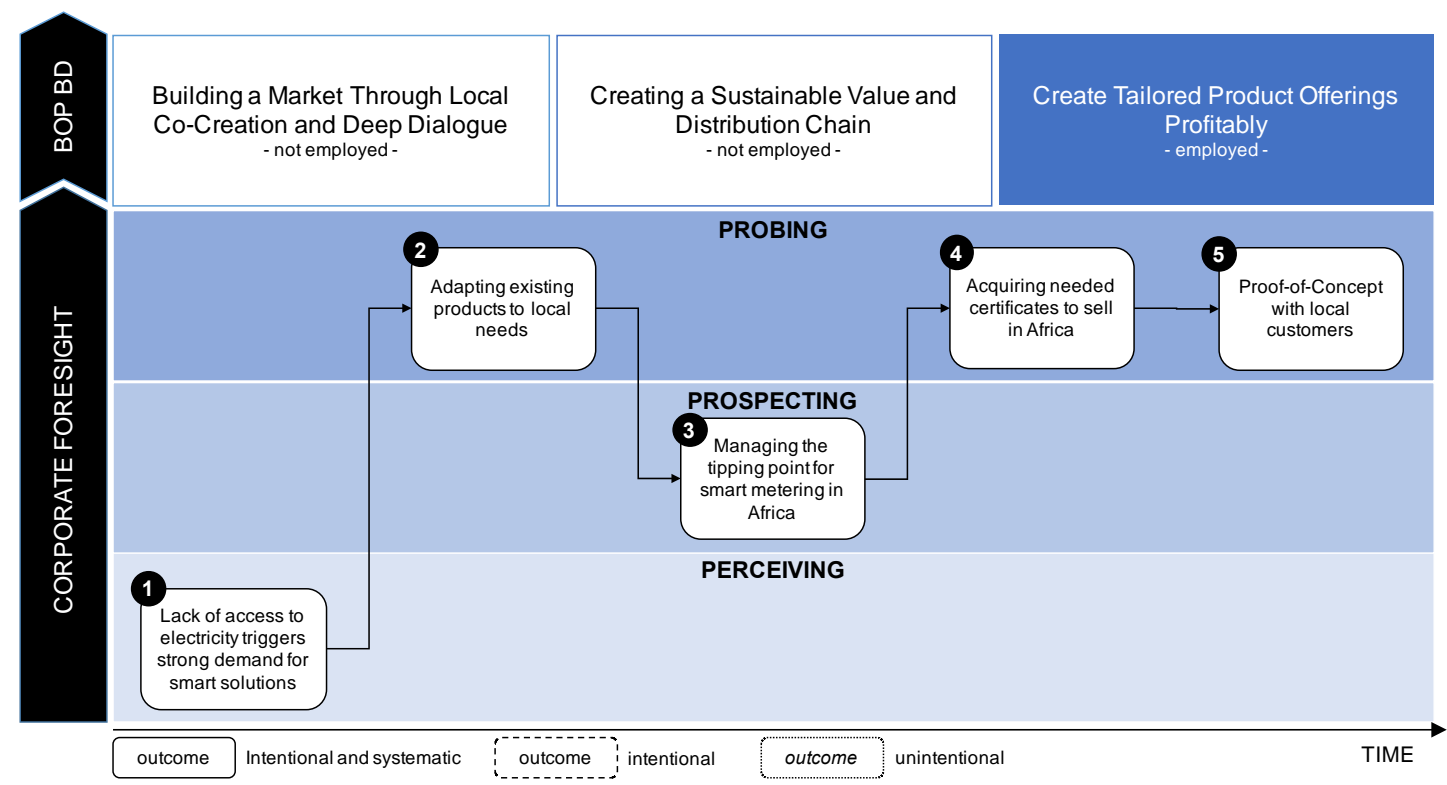

Figure 3: Business development sequence - Kamstrup

Through working with the local customers, Kamstrup could substantiate that a tipping point is approaching. Consequently, they moved to the next probing phase (step 4) towards acquiring the necessary certificates for a number of African countries. With the certificates in hand, 
they could reengage with the customer, with whom they had already, during the prospecting phase, built a deep relationship, and move towards the proof-of-concept (PoC) phase (step 3). Such PoCs include a 200-device pilot project in Kenya. To invest in large-scale deployments, these probing activities are essential; as the head of sales explains: 'Here you get to see reality and know the customer, the environment of the metering device, and pressure test your product to make sure that it can perform, so you will also increase customer confidence that the product will solve his business issue.'

From the BOP business-development paths,

- The creation of tailored solutions through the PoC phase was particularly pronounced. The product needed to be adapted to African needs, and Kamstrup worked towards that goal directly with the local utilities. This work was needed, as the customers in Africa were faced with very different challenges and thus needed different value propositions, e.g., increased access to energy in Africa vs. increased energy efficiency in Europe.

\subsection{Multinational corporation in food \& beverages industry (Arla)}

Our last case, Arla, is a global dairy company. Their products are fast-moving consumer goods, for which prices are low but volumes are high. Arla operates in markets that need high degrees of product adaptations to the specific needs and tastes of the local consumer groups. Figure 4 shows the business-development sequence that led to this market success.

The perception phase (step 1) of this success story begins with a lack of perception of a strategic surprise, i.e., the weak signals have remained undetected, and the strategic surprise was only spotted in the fait-accompli state. This strategic surprise was the removal of subsidies that were the basis for the profitable business case of shipping European milk to Africa. The logical consequence would have been to pull out of the market as quickly as possible. Through intentional, but at the start, mostly unstructured perceiving (step 2) Arla identified two key trends: the growing middle class and the removal of trade barriers, which could eventually lead towards a very attractive future market. However, it was also clear that in the short-term, a solution needed to be found to drastically reduce production costs. This solution was found through prospecting (step 3). As a first insight, it became clear that a new solution would need to meet three criteria to be considered a viable BOP product: (i) it needs to have a 'long life' because otherwise it could not be produced on the basis of European milk and shipped to Africa, (ii) it needs to be 'ambient', i.e., it has to be possible to store and distribute without cooling and (iii) it needs to be 'affordable'. The solution was milk powder, which had the same nutritional qualities as whole milk powder but in which the milk fat was substituted by vegetable fat, which drastically lowered the production cost.

The first probing phase (step 4) was thus mainly concerned with developing the right formula for the milk and developing the production process. The second phase of probing (step 5) was prototyping the production to start going through the official approval tests to gain market access. After gaining the necessary certificates, the market development went smoothly, and Arla became a market leader in a number of regions in Nigeria. However, unexpected competitor lawsuits resulted in an injunction that prevented Arla from selling its product. Through an additional prospecting effort (step 6), it was possible to adapt the design and circumvent the injunction. 


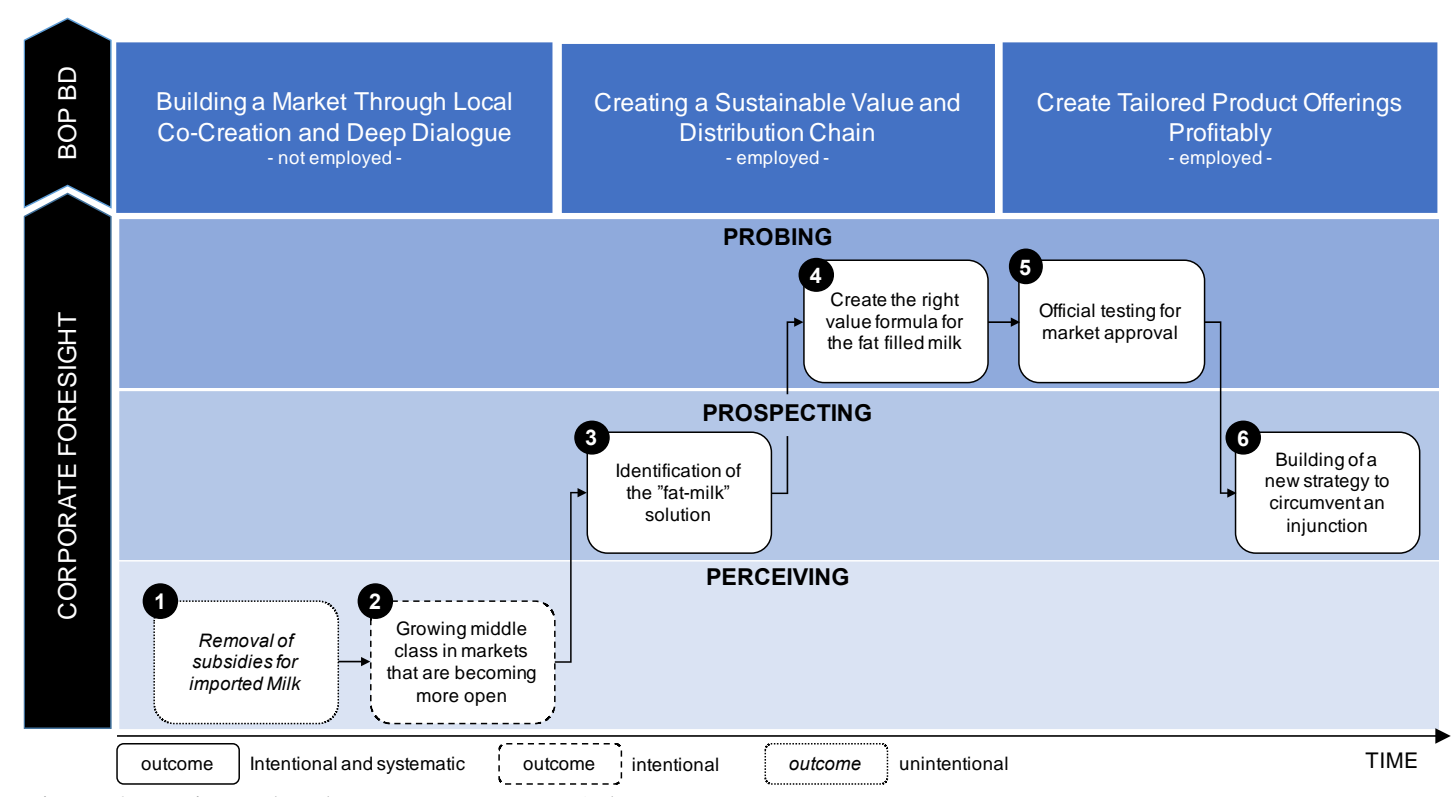

Figure 4: Business development sequence - Arla

Another interesting aspect in the case was the comprehensive application of the BOP business-development paths.

- Arla has been successful in building the market through local co-creation, in particular through multiple rounds of consumer tests in Africa. Here, Arla investigated and cocreated product characteristics, such as taste, size and price point.

- Arla had earlier understood the need to tailor its offerings, leading to the low-cost, fatfilled formula. In addition, effort also went into adapting the milk's taste to local preferences.

- More importantly, they understood that large-quantity packaging could be an to buy the product. This insight led to the development of 6-g single-serving packages that worked well for consumers in BOP markets. However, another challenge was that this packaging and the associated distribution system would become too expensive if the packaging needed to occur in Europe. A solution was to build a local packaging site that formed the basis for a local value and distribution chain. This solution allowed positioning the product in the low-cost market and, as an additional benefit, led to local job creation, which was seen as a highly valued local engagement that in turn boosted the credibility of Arla as a firm and the brand attachment.

\subsection{Cross-Case Analysis}

In the cross-case analysis we first looked for patters by systematically going through the firm characteristics. When looking for effects from industry on CF practices, theory would expect to find more intentional and systematic practices in industries prone to disruptions (Müller and Müller-Stewens 2008; Sarpong and O'Regan 2014). In our case, Kamstrup, from an industry with a high level of disruption, has indeed been more active than Arla, which operates in a comparably low-disruptive environment. Evershelter operates in an industry that is highly regulated and dependent on political influences. The initial idea and a great amount of the prospecting has consequently been focused on the political level, relying, for example, on UN reports. The higher deployment of systematic foresight techniques can, in the case of Kamstrup, also have resulted from the need for heavy investments in technology development and systems integration, which translates into pressure to seek economies of scale by expanding globally.

When looking for effects from the nature of the product, we would expect that technologypush products would be complemented by market perceiving and prospecting activities (Hofmann 2015), which was also the case for Kamstrup. For market-pull products, dedicated 
scouting for technology would be expected. In Evershelter, that also occurred, while in the case of Arla, it was more a matter of using internal technological capabilities to build the new BOP product. We also found that the products that existed and were then adapted to Africa relied more on probing (experimental search) and less on prospecting (cognitive search). However, this might also reduce their impact, as their positioning might be closer to the current products than what cognitive search might have revealed.

The expected effects of size would be that the larger a firm is, the more likely it would be to have established formal CF capabilities (Schwarz 2008; Daheim and Uerz 2008). Large firms need to protect assets and ensure that the firm can renew its competitive advantage (Ruff 2015; Boe-Lillegraven and Monterde 2015; Hines and Gold 2015; Rohrbeck, Arnold, and Heuer 2007). In that respect, it comes as a surprise that the monitoring of the political situation, which led to the removal of subsidies, was not perceived early in the Arla case. However, the following prospecting and probing mechanisms were still potent enough to save the market and allow Arla to attain a market-leader position with its new product. On the other end of the size scale, Evershelter conducted its foresight activities in a more ad-hoc and on-demand fashion.

The ownership structure is a relatively unexplored influencing factor. However, we enter the field with the expectation that privately or cooperatively owned companies are more likely to take a long-term investment perspective than shareholder-owned firms, and consequently, that they would be more interested in investing in CF (van der Duin and Hartigh 2009). In our case, we attest that the influence of ownership structure is weak and overridden by other factors. In particular, in the comparison of Arla and Kamstrup, we see that the nature of the product has mostly led to Arla being less invested in structured foresight approaches than Kamstrup.

In addition to the influence of firm characteristics, we wanted to search for patterns in the business-development sequence. Here the first notable commonality was that all firms underwent iterations within the 3 Ps (perceiving, prospecting, and probing) of CF. The implication is that firms need to stay persistent when exploring new markets with foresight and be ready to iterate between thinking (perceiving, prospecting) and acting (probing). Explained differently, they can profit from feedback loops between cognitive and experimental search activities.

To differentiate the extent to which the actual business-development activities match with the prescriptions of CF practices, we introduced the following levels: a) unintentional (no formal $\mathrm{CF}$ activities and no planned, deliberate effort), intentional (still no formal CF practices but planned and deliberate) and intentional and systematic (purposefully exercised CF practice). We find that CF practices were only in one out of three cases the trigger for the businessdevelopment activity. In all cases, we find intended and systematic CF activities somewhere in the business-development sequence (typically in the second half of the sequence). This finding suggests firms' weakness to repeatedly and systematically trigger new businessdevelopment. It also shows that once triggered, the firms can rely more on established and effective CF methods and tools. This finding resonates well with the suggestion of the innovation's fuzzy-front-end literature that the main differentiator between average and outperforming firms might be in the degree of mastery of the early and initial phases (Rohrbeck 2013; Price et al. 2009).

In addition, we find that when complexity and uncertainty is high, firms tend to engage in early and extensive probing (experimental search) activities. This is insofar justified that CF requires a certain level of predetermination, i.e., justified expectations about the direction and rate of change (Van der Heijden 2005). However, it carries the risk that the identified opportunities are not sufficiently distant to the current market to carry superior value creation 
potential. As Gavetti and Levinthal (2000) emphasize, cognitive search (perceiving and prospecting) is more potent than experimental search to uncover distant alternatives.

\section{Discussion}

The aim of our study was to investigate the extent to which actual and successful businessdevelopment activities can be classified as CF and the extent to which they have been intentional and systematic. We placed our empirical investigation in BOP markets deliberately for two reasons. First, we see these markets as being particularly relevant for creating value for firms and societies alike. Second, we use them as an environment with a high level of uncertainty and as markets where firms have very limited past experience.

To boost generalizability, we selected cases that were very different from each other, which limited our ability to use replication for the validation of our findings. Our findings are thus more indicative than conclusive. The phenomena we found and discussed should be thus subject to further analysis.

Our research approach is heavily reliant on timelines, which we constructed through secondary data (internal and external reports and documents), actor interviews (with two respondents per case) and interviews with external observers and Africa experts. This allowed us to ensure a moderate level of triangulation, which reduced a potential single-source bias. However, the retrospect bias could have negatively influenced our data. Future studies could overcome these limitations by using more data-collection techniques, such as observations, diaries and more detailed documents, such as minutes of key meetings, project presentations and email-based discussions.

\section{Conclusion}

With this article, we want to contribute to our understanding of the impact of CF activities. While research on CF has typically taken its starting point in observing intended and systematic approaches (Ruff 2006; Peter and Jarratt 2015), we started from the other direction. This provides us with an interesting vantage point from which we can systematically challenge the wisdom that CF activities contribute to the exploration success of a firm.

We find that in our sample, firms were using systematic CF methods only rarely in the early phases, suggesting that there is a high risk that opportunities remain unidentified and consequently unexplored and unexploited. In the latter phases, however, more systematic activities are conducted that include scanning for and matching of technology and market changes and systematically constructing value formulas and business models.

We further found that the successful cases went through multiple iterations of perceiving, prospecting and probing, suggesting that successful business development is a non-linear process that builds on feedback loops and requires persistence. For theory our finding suggests that cognitive and experimental search mechanisms must be combined to create effective exploration capabilities (Gavetti and Levinthal 2000). This could permit overcoming the weaknesses of the one search mode, e.g., the inability to identify distant opportunities with experimental search, with the strengths of the other search mode, e.g., the ability to use cognitive search to overcome the experience bound.

The setting in the BOP markets placed us empirically in a high uncertainty environment, which forms a stark contrast towards business development in developed countries and markets, in which, for most, driving factors have a high level of predetermination and data availability is high. In this context, we can attest that firms relied heavily on early and extensive probing activities. These experimental search activities seemed to have a dual role. 
First, they provided tangible POCs, which aid in decision making. Second, they allowed the generation of insights into market and technology aspects that would ex-ante not have been judged to be relevant.

In conclusion, we expect that also outside our investigation scope, the BOP markets, the importance of probing activities has been underestimated. While traditional CF literature prescribes many methods, tools and practices for cognitive search (perceiving and prospecting), we conclude that in future investigations, we need to pay more attention to the need for and benefits of experimental search (probing).

\section{References}

Becker, Patrick. 2002. "Corporate Foresight in Europe: A First Overview." In Working Paper European Commission, 31. Brussels: European Commission.

Boe-Lillegraven, Siri, and Stephan Monterde. 2015. "Exploring the cognitive value of technology foresight: The case of the Cisco Technology Radar." Technological Forecasting and Social Change 101:62-82. doi: http://dx.doi.org/10.1016/j.techfore.2014.07.014.

Coates, Joseph, Philippe Durance, and Michel Godet. 2010. "Strategic Foresight Issue: Introduction." Technological Forecasting and Social Change 77 (9):1423-5. doi: 10.1016/j.techfore.2010.08.001.

Daheim, Cornelia, and Gereon Uerz. 2008. "Corporate foresight in Europe: from trend based logics to open foresight." Technology Analysis \& Strategic Management 20 (3):32136.

Dansk Industri. 2007. "Working with the BOP - Success in Low Income Markets." In. Copenhagen, Denmark: Dansk Industri.

Day, George S., and Paul J. H. Schoemaker. 2004. "Driving Through the Fog: Managing at the Edge." Long Range Planning 37 (2):127-42.

Eisenhardt, K. M. 1989. "Building Theories from Case-Study Research." Academy of Management Review 14 (4):532-50.

Eriksson, P. , and A. Kovalainen. 2008. Qualitative Methods in Business Research. London, UK: SAGE.

Flyvbjerg, B. 2006. "Five misunderstandings about case-study research." Qualitative Inquiry 12 (2):219-45. doi: 10.1177/1077800405284363.

Gavetti, G. 2012. "Toward a Behavioral Theory of Strategy." Organization Science 23 (1):267-85. doi: 10.1287/orsc.1110.0644.

Gavetti, Giovanni, and Daniel Levinthal. 2000. "Looking forward and looking backward: Cognitive and experiential search." Administrative Science Quarterly 45 (1):113-37.

Gavetti, Giovanni, and Anoop Menon. 2016. "Evolution Cum Agency: Towards a Model of Strategic Foresight." Strategy Science 1 (3):207-33.

Heger, Tobias, and René Rohrbeck. 2012. "Strategic Foresight for Collaborative Exploration of New Business Fields." Technological Forecasting and Social Change 79 (5):81931.

Hines, Andy, and Peter Bischop. 2006. Thinking about the Future: Guidelines for Strategic Foresight. Washington, DC: Social Technologies.

Hines, Andy, and Jeff Gold. 2015. "An organizational futurist role for integrating foresight into corporations." Technological Forecasting and Social Change 101:99-111. doi: http://dx.doi.org/10.1016/j.techfore.2014.04.003.

Hofmann, Rupert. 2015. "Visionary competence for long-term development of brands, products, and services: The trend receiver concept and its first applications at Audi." Technological Forecasting and Social Change 101:83-98. doi: http://dx.doi.org/10.1016/j.techfore.2014.06.005.

Johnson, Mark W., Clayton M. Christensen, and Henning Kagermann. 2008. "Reinventing your business model." Harvard Business Review 86 (12):57-68. 
Müller, Adrian W., and Günter Müller-Stewens. 2008. Strategic Foresight: Trend- und Zukunftsforschung in Unternehmen - Instrumente, Prozesse, Fallstudien. Stuttgart: Schäffer-Poeschel.

Peter, Marc K., and Denise G. Jarratt. 2015. "The practice of foresight in long-term planning." Technological Forecasting and Social Change 101:49-61. doi: http://dx.doi.org/10.1016/j.techfore.2013.12.004.

Prahalad, Coimbatore K, and Stuart L Hart. 2002. "The Fortune at the Bottom of the Pyramid." Strategy and Business 26:2-14.

Price, RL, A Griffin, BA Vojak, and N Hoffmann. 2009. "Innovation politics: how serial innovators gain organisational acceptance for breakthrough new products." International Journal of Technology Marketing 4 (2):165-84.

Rohrbeck, René. 2010a. Corporate Foresight: Towards a Maturity Model for the Future Orientation of a Firm. Heidelberg: Physica-Verlag, Springer. . 2010b. "Harnessing a network of experts for competitive advantage - Technology Scouting in the ICT Industry." $R \&$ D Management 40 (2):169-80.

. 2012. "Exploring value creation from corporate-foresight activities." Futures 44 (5):440-52.

2013. "Trend Scanning, Scouting and Foresight Techniques." In Front End of Innovation: Managing the Unmanagable Fuzzy Side, edited by Fiona Schweitzer Oliver Gassmann. Heidelberg, Berlin: Springer.

Rohrbeck, René, Heinrich Arnold, and Jörg Heuer. 2007. Strategic Foresight in multinational enterprises - a case study on the Deutsche Telekom Laboratories. Paper presented at the ISPIM-Asia 2007 Conference.

Rohrbeck, René, Cinzia Battistella, and Eelko Huizingh. 2015. "Corporate foresight: An emerging field with a rich tradition." Technological Forecasting and Social Change 101:1-9. doi: http://dx.doi.org/10.1016/j.techfore.2015.11.002.

Rohrbeck, René, Mario Döhler, and Heinrich Arnold. 2009. "Creating growth with externalization of R\&D results - the spin-along approach." Global Business and Organizational Excellence 28 (4):44-51.

Rohrbeck, Rene, and Hans Georg Gemünden. 2011. "Corporate Foresight: Its Three Roles in Enhancing the Innovation Capacity of a Firm." Technological Forecasting and Social Change 78 (2):231-43.

Rohrbeck, René, Menes Etingue Kum, and Tymen Jissink. 2017. "Corporate Foresight: Benchmarking Report 2017." In. Aarhus, Denmark: Aarhus University, Aarhus School of Business and Social Sciences.

Rohrbeck, René, and Jan Oliver Schwarz. 2013. "The Value Contribution of Strategic Foresight: Insights From an Empirical Study of Large European Companies." Technological Forecasting and Social Change 80 (8):1593-606.

Rubin, HJ, and I Rubin. 2005. Qualitative interviewing: The art of hearing data, Thousand Oaks. CA: Sage.

Ruff, Frank. 2006. "Corporate foresight: integrating the future business environment into innovation and strategy." International Journal of Technology Management 34 (34):278-95.

2015. "The advanced role of corporate foresight in innovation and strategic management - Reflections on practical experiences from the automotive industry." Technological Forecasting and Social Change 101:37-48. doi: http://dx.doi.org/10.1016/j.techfore.2014.07.013.

Sarpong, David, and Nicholas O'Regan. 2014. "The Organizing Dimensions of Strategic Foresight in High-Velocity Environments." Strategic Change 23 (3-4):125-32. doi: $10.1002 /$ jsc. 1965 .

Saunders, Mark, Philip Lewis, and Adrian Thornhill. 2007. Research methods for business students. 4th ed. Harlow, England ; New York: Financial Times/Prentice Hall.

Schwarz, Jan Oliver. 2008. "Assessing the future of futures studies in management." Futures 40 (3):237-46. 
Simanis, E., and S. L. Hart. 2008. The Base of the Pyramid Protocol - Towards Next Generation BOP Strategy: Cornell University.

Slaughter, Richard A. 1997. "Developing and Applying Strategic Foresight." ABN Report 5 (10):13-27.

Tsoukas, H., and J. Shepherd. 2004. "Coping with the future: developing organizational foresightfulness - Introduction." Futures 36 (2):137-44.

van der Duin, Patrick, and E. den Hartigh. 2009. "Keeping the balance. Exploring the link of futures research with innovation and strategy processes." Technology Analysis \& Strategic Management 21 (3):333-51.

Van der Heijden, Kees. 2005. Scenarios : the art of strategic conversation. 2nd ed. Chichester, West Sussex ; Hoboken, N.J.: John Wiley \& Sons.

Vecchiato, Riccardo. 2015. "Creating value through foresight: First mover advantages and strategic agility." Technological Forecasting and Social Change 101 (25-36). doi: http://dx.doi.org/10.1016/j.techfore.2014.08.016.

Vecchiato, Riccardo, and Claudio Roveda. 2010. "Strategic foresight in corporate organizations: Handling the effect and response uncertainty of technology and social drivers of change." Technological Forecasting and Social Change 77 (9):1527-39.

Winter, Sidney G. 2004. "Specialised Perception, Selection, and Strategic Surprise: Learning from the Moths and Bees." Long Range Planning 37 (2):163-9.

Yin, Robert K. 2003. Case study research: design and methods. 3rd ed, Applied social research methods series ;. Thousand Oaks, Calif.: Sage Publications. 